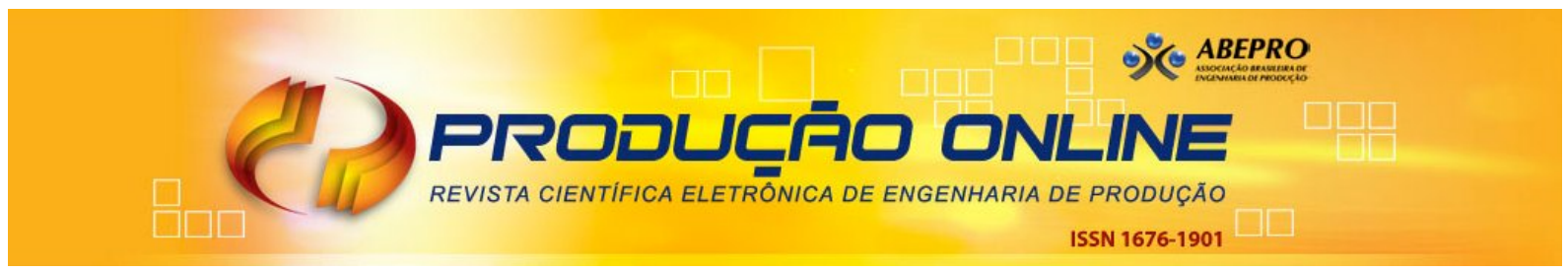

\title{
A INFLUÊNCIA DAS PRÁTICAS DE PRODUÇÃO ENXUTA NOS ATRIBUTOS QUALIFICADORES DAS CÉLULAS DE MANUFATURA
}

\section{THE INFLUENCE OF LEAN MANUFACTURING PRACTICES IN CELLULAR MANUFACTURING QUALIFYING ATTRIBUTES}

\author{
Giuliano Marodin* E-mail: gmarodin@producao.ufrgs.br \\ Tarcísio Abreu Saurin* E-mail: saurin@producao.ufrgs.br \\ *Universidade Federal do Rio Grande do Sul (UFRGS), Porto Alegre, RS
}

\begin{abstract}
Resumo: O objetivo deste artigo é investigar como as práticas de Produção Enxuta (PE) influenciam no desempenho da célula de manufatura (CM), baseado no estudo teórico sobre os atributos que qualificam uma CM. Para isto, foi necessário desenvolver um conceito de CM que atenda a perspectiva do sistema sócio-técnico, incorporando um atributo técnico e outro social, e também a presença dos elementos de tempo, espaço e informação, que definem uma "célula real". Como resultado, se evidencia que a maioria das práticas de PE tem como objetivo aumentar a presença dos elementos de tempo e informação nas CM. Seja pela detecção rápida de problemas, na atuação na solução de problemas ou no uso de uma quantidade de estoques mínima entre as atividades da célula, a PE busca formar uma unidade gerencial que simultaneamente reduza o tempo de processamento e informe constantemente sobre a situação de todos os recursos. Apesar de influenciar em um menor grau, o atributo organizacional e o elemento espaço também são influenciados positivamente pela aplicação das práticas de PE.
\end{abstract}

Palavras-chave: Produção Enxuta. Lean Manufacturing. Manufatura Celular. Célula de Manufatura

\begin{abstract}
This article aims to investigate how of lean production (LP) influences to a manufacturing cell (MC) performance, based on the theoretical study about the attributes that characterize a MC. It was necessary to develop the concept of $\mathrm{MC}$ in a socio-technical system perspective, incorporating a technical attribute, a social attribute and the elements of time, space and information to define a "real cell". The results show that most of LM practices aim to increase time and information. The rapid problem solving process and the use of minimal amount of inventory between the activities of the cell seeks to simultaneously reduces the processing time and increase the degree of information. Although influenced to a lesser degree, the organizational attribute and space element are also positively influenced by the practical application of PE.
\end{abstract}

Keywords: Lean Production. Cellular Manufacturing.

\section{INTRODUÇÃO}

As células de manufatura (CM) são amplamente difundidas em empresas que adotam os princípios e práticas de Produção Enxuta (PE) (HYER; WEMMERLOV, 
2002). De fato, são disponíveis diversos estudos que relatam ou sugerem a transição de arranjos físicos funcionais para CM como parte dos esforços na transformação enxuta (WOMACK; JONES, 1998; ROTHER; HARRIS, 2002; MOTWANI, 2003; LIKER, 2005; BLACK, 2007; PATTANAIK, SHARMA, 2009; PETTERSEN, 2009). Tais trabalhos têm sido frequentes, pois algumas características dos arranjos funcionais, tais como os grandes estoques intermediários, pouca transparência de processos e grandes lotes de produção, são incompatíveis com os objetivos da PE. Segundo Monden (1998) as CM propiciam ao sistema de manufatura as seguintes características: (a) agilidade para se adaptar às variações de mix e volume de produção, em função do seu tamanho e forma compacta que permite diversas opções de alocação dos operadores multifuncionais; (b) redução de lead time, uma vez que células implicam em arranjos físicos por produto, com os recursos dispostos segundo a sequência de processamento. Essas características estão diretamente relacionadas a dois dos cinco princípios essenciais da PE por Womack e Jones (1998), a produção puxada e o fluxo contínuo.

Para Sheridan (1990), a CM é uma poderosa alternativa para reduzir tempos de esperas, lead times, custos e melhorar a qualidade, sendo que estes são objetivos típicos da PE. Além disso, o fato de uma CM ser uma pequena unidade do sistema de manufatura, muitas vezes independente de outras áreas produtivas da fábrica, torna mais simples a aplicação integrada dos princípios e práticas da PE (SAURIN; MARODIN; RIBEIRO, 2011).

Os estudos que abordam as interfaces entre CM e PE têm tido três enfoques principais: (a) o projeto de $\mathrm{CM}$ que incorporam princípios de $\mathrm{PE}$, a partir de arranjos funcionais (ROTHER; HARRIS, 2002; BLACK, 2007; PATTANAIK; SHARMA, 2009) ou linhas de produção (GHINATO, 1998); (b) a descrição das características de operação de CM que adotam as práticas e princípios de PE (WOMACK; JONES, 1998; MILTENBURG, 2001); (c) a descrição de práticas individuais que podem ser utilizadas em CM, como as práticas de medição de desempenho (MASKELL; BAGGALEY, 2004), quadros para controle de produção e de qualidade (HENDERSON; LARCO, 1999) ou arranjos físicos e treinamento da mão-de-obra (MONDEN, 1998). Embora a literatura indique de modo genérico que os princípios e práticas da $\mathrm{PE}$ são plenamente 
compatíveis com os princípios de $\mathrm{CM}$, há carência de estudos que aprofundem a discussão acerca das interfaces entre PE e CM, considerando as interações entre as práticas de $\mathrm{PE}$ no microambiente da $\mathrm{CM}$.

Uma das dificuldades do estudo destas interfaces está na própria definição dos dois conceitos, amplamente discutida na literatura. Em relação a $\mathrm{CM}$, esta é muitas vezes conceituada de maneira limitada, como apenas um arranjo físico (HYER; BROWN, 1999). Este conceito vem sendo criticado, dentre outros motivos, por focar apenas em dimensões técnicas, deixando de lado a dimensão humana e as características de um sistema sócio-técnico (HYER; BROWN; ZIMMERMAN, 1999). Segundo Wemmerlov e Johnson (1997) os fatores humanos, como envolvimento do empregado, liderança e rodízio, estão entre as variáveis menos discutidas em processos de implantação de células, embora possam ter um grande impacto em seus resultados. Em outra perspectiva, existem diversas variações possíveis na aplicação da $\mathrm{CM}$ em função dos diferentes ambientes produtivos, fato não contemplado na maioria das definições de CM presentes na literatura (HYER; BROWN, 1999). As autoras propõem uma definição de $\mathrm{CM}$ baseada na aderência a interação entre três elementos que definem uma "célula real". A aderência segundo tais elementos foi utilizada para avaliar células no ambiente de manufatura (MARODIN; SAURIN, 2007) e na construção civil (SANTOS; MOSER; TOOKEY, 2002).

Por outro lado, a PE também sofre desta mesma limitação, pois a literatura não apresenta um consenso em relação à estrutura conceitual da PE (HINES; HOLWEG; RICH, 2004; PAPADOPOULOU; OZBAYRAK, 2005; CARDOZA; CARPINETTI, 2005). Diversos estudos abordaram práticas e princípios do Sistema Toyota de Produção (STP) e a PE de modo sistêmico em diferentes pontos de vista, seja em uma literatura voltada para os práticos, ou seja, em livros sem um rigor científico (OHNO, 1997; SHINGO, 1996; MONDEN, 1998; WOMACK; JONES, 1998; LIKER, 2005), ou em trabalhos voltados para a academia, ou seja, com uma maior preocupação científica (GODINHO FILHO; FERNANDES, 2004; HINES; HOLWEG; RICH, 2004; NOGUEIRA; SAURIN, 2008; PETTERSEN, 2009). A abundância de definições e estruturas para a 
PE gera a necessidade de se definir quais das práticas de PE interagem diretamente com a CM.

Desta forma, o presente artigo teve como objetivo responder a seguinte questão de pesquisa:

Como as práticas de PE influenciam nos atributos qualificadores de uma $\mathrm{CM}$ ?

No intuito de alcançar tal objetivo, foi necessário primeiro definir quais são os atributos que qualificam uma $\mathrm{CM}$, de forma a atender a evolução do tema. Após, definir quais são as práticas de PE que podem ser aplicadas nas CM e como tais práticas auxiliam nestes atributos.

\section{REFERENCIAL TEÓRICO}

\subsection{Células de Manufatura}

\subsubsection{Linhas gerais}

Hyer e Brown (1999) argumentam que a definição de CM evoluiu desde a sua criação, na União Soviética durante a década de 30, o que pode ter contribuído para o surgimento de divergências ao longo desse período. Na sua concepção, a CM foi definida como um agrupamento de diferentes máquinas que permitem a produção de um conjunto de produtos similares em pequenos ou médios lotes (DROLET; ABDULNOUR; RHEAULT, 1996). Burbidge (1996) acrescenta que a CM deve conter todos os recursos físicos necessários para a fabricação de um grupo de produtos.

Os atributos que qualificam a CM apresentados a seguir foram baseados no conceito da concepção da CM e nas definições presentes em Hyer e Brown (1999) e Hyer e Wemmerlov (2002). Os atributos incorporam interações pertinentes a um sistema sócio-técnico. 


\subsubsection{Atributo de tecnologia de grupo}

Este atributo se refere a duas características importantes nas $\mathrm{CM}$, presente nas definições de Hyer e Brown (1999) e Hyer e Wemmerlov (2002) e que se referem a aspectos ligados à definição inicial de $\mathrm{CM}$, sendo elas: (a) as operações presentes na célula devem ser diferentes e sequenciais; (b) essas operações devem ser dedicadas a uma família de produtos similares que compartilhem as operações e fluxos de produção. Hyer e Wemmerlov (2002) enfatizam que embora essas sejam características chave para o desempenho da $\mathrm{CM}$, com frequência são observadas células em que os recursos são compartilhados com outras células e arranjos funcionais.

A característica (a) reflete a diferença entre a célula de manufatura e o arranjo físico funcional, no qual um único tipo de operação é realizado. Vale ressaltar que, para Shafter, Meredith e Marsh (1995), uma célula pode até mesmo ser constituída de equipamentos iguais, desde que os mesmos realizem operações diferentes de forma sequencial. Em relação à quantidade de operações, uma célula ideal deveria reunir todas as etapas necessárias para a fabricação de todo o produto, das matérias primas ao produto final, fato este que, na prática, dificilmente se torna economicamente viável (HYER; WEMMWELOV, 2002).

A segunda característica deste atributo pode ser mais bem compreendida com base no conceito de tecnologia de grupo (TG), o qual é essencial no projeto e funcionamento da CM (RAO et al., 2001). A TG é definida como uma forma de organização da produção que visa a redução da complexidade e obtenção de economia de escala, por meio do agrupamento de produtos similares em um mesmo arranjo físico (BURBIDGE, 1996). A similaridade tende a facilitar o gerenciamento conjunto de ferramentas e equipamentos, setups, operações e tempos de produção (COELHO; BRANCO; RODRIGUES, 2006). 
2.1.3 Atributos ligados às conexões de tempo, espaço e informação

Hyer e Brown (1999) propuseram uma nova conceituação de CM, desenvolvida para abranger o fato de que um grande número de aplicações encontradas na prática era diferente do conceito inicial de $\mathrm{CM}$. As autoras também perceberam que a grande diversidade de $\mathrm{CM}$ em diferentes indústrias exigia um conceito mais abstrato. A CM seria caracterizada por um fluxo de trabalho em que existam conexões de tempo, espaço e informação entre as atividades e entre aqueles que as realizam. A célula definida como "real" se caracteriza pelo alto grau de interação entre os três elementos.

No que se refere ao elemento tempo, uma célula real deve ter pouco atraso entre o final de uma tarefa e o início da próxima, além do baixo tempo de transferência e espera. O elemento espaço implica na proximidade dos equipamentos e operadores, a fim de facilitar a transferência de materiais, troca de informações e resolução rápida de problemas. Em relação ao elemento informação, em uma célula real as informações devem ser completas, precisas e acessíveis a todos, indicando metas, pedidos, especificações, procedimentos e disponibilidade de componentes (HYER; BROWN, 1999).

Para Hyer e Brown (1999), a relação entre tempo e informação é a mais dinâmica dentre todas, visto que informações completas e disponíveis podem diminuir e equilibrar os tempos de ciclo. O espaço também influencia nas trocas de informação, pois a proximidade de pessoas, máquinas e processos aumenta o potencial de comunicação entre os operadores. Essa troca de informações permite que os operadores tomem conhecimento sobre o nível de estoque, problema de qualidade, postos gargalo, falta de componentes e outros fatores-chave do desempenho da célula. A redução de atrasos no transporte de componentes entre estações de trabalho faz da conexão espaço-tempo mais uma importante relação na CM. Quanto maior a distância que um componente precisa percorrer, maior a probabilidade de atraso na produção por espera de material, envio a um local errado ou ocorrência de danos durante o manuseio (HYER; BROWN, 1999). 
Dentre os fatores que influenciam essas conexões estão o número de operadores e as dimensões do arranjo físico. Embora não haja consenso relativo à quantidade máxima de operadores que caracterize uma CM, Hyer e Wemmerlov (2002) indicam que o número ideal é entre 4 a 6 pessoas, sendo, no máximo, 15 pessoas, para que seja viável o trabalho em equipe. Aqueles autores acrescentam que tanto a falta de operadores como o excesso pode prejudicar o fluxo de trabalho na CM. Para Hyer e Brown (1999), independente da quantidade de operadores, o tamanho da célula não deve prejudicar o controle visual dos operadores, máquinas e fluxo de produção.

Similarmente ao que ocorre em relação ao número de operadores, Hyer e Wemmerlov (2002) consideram que não há rigidez no quão próximo os recursos devem ser posicionados. Entretanto, as linhas de produção com frequência podem ser diferenciadas das células, uma vez que as estações de trabalho estão distantes umas das outras, de modo que os operadores em uma parte da linha não conseguem enxergar, se comunicar, entender o status do trabalho e auxiliar outros operadores. Se os operadores não estiverem aptos a se comunicar uns com os outros como uma equipe, serão incapazes de transmitir informações sobre falta de peças, problemas de ferramentas, qualidade, entre outros (HYER, WEMMERLOV, 2002). Desta forma, as linhas de produção normalmente têm fracas conexões em termos de informação e espaço.

A forma do arranjo físico costuma contribuir bastante para a caracterização da $\mathrm{CM}$, visto que alguns formatos favorecem o contato visual, reduzem deslocamentos e proporcionam maiores opções de alocação de operadores aos postos de trabalho, facilitando as conexões de tempo e informação (HYER; BROWN, 1999)

A célula real apresenta uma harmonia entre os elementos tempo, espaço e informação, entretanto, existem células que funcionam de maneira eficaz mesmo sem aderir à disciplina das células reais. Estas células são classificadas conforme o elemento que se encontra deficiente. Hyer e Brown (1999) apresentam uma classificação em cinco categorias adicionais: (a) física latente deficiente em informação; (b) física latente deficiente em informação e tempo; (c) física latente deficiente em tempo; (d) virtual latente deficiente em espaço e tempo; (e) virtual deficiente em espaço. 
Apesar da importante contribuição teórica, a aplicação prática do conceito de Hyer e Brown (1999) tende a ser complexa, uma vez que os fatores tempo, espaço e informação são difíceis de serem avaliados diretamente. Tendo isso em vista, Hyer e Brown (1999) propuseram exemplos de capacitadores que viabilizam as conexões entre os três elementos citados (Figura 1 ).

Figura 1 - Interação entre capacitadores e elementos em CM

\begin{tabular}{|c|c|c|c|}
\hline CAPACITADORES & TEMPO & ESPAÇO & INFORMAÇÃO \\
\hline Tamanho de lote pequeno & • & & $\cdot$ \\
\hline Transporte de peças em lotes pequenos & - & + & + \\
\hline Peças entregues em tempo & $\bullet$ & & \\
\hline Recebimento de material conforme as especificações & - & & \\
\hline Manuseio eficaz de equipamentos e processos & $\bullet$ & & \\
\hline Tempo de Setup reduzido & $\bullet$ & & + \\
\hline Postos de trabalho balanceados & $\bullet$ & & $\cdot$ \\
\hline Tamanho da célula pequeno & $\bullet$ & - & $\bullet$ \\
\hline Treinamento multifuncional e rodizio & $\bullet$ & & $\bullet$ \\
\hline $\begin{array}{l}\text { Justaposição de equipamentos arranjados seqüencialmente } \\
\text { equipamento em células organizadas para acomodar fluxo dominante }\end{array}$ & $\bullet$ & $\bullet$ & $\bullet$ \\
\hline Miniaturizaça a de processos considerados "monumento" & $\cdot$ & $\bullet$ & $\cdot$ \\
\hline Equipamento que pode ser movido quando célula precisa mudar & 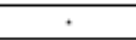 & $\bullet$ & . \\
\hline Manutenção preventiva & - & & \\
\hline Os operadores especializados na manutenção autônoma & - & & + \\
\hline Boas relações interpessoais entre os operadores & + & & $\bullet$ \\
\hline Operadores compartilham informaços continuamente & + & & $\bullet$ \\
\hline Os operadores especializados em trabalho em grupo & + & & $\bullet$ \\
\hline $\begin{array}{l}\text { Os operadores têm acesso visual a todas as atividades da célula } \\
\text { informação na "linha de visão" }\end{array}$ & $\cdot$ & & $\bullet$ \\
\hline Os operadores têm entendimento de "toda tarefa" & + & & $\bullet$ \\
\hline $\begin{array}{l}\text { Gestão de sistemas de controle visual, auditiva manual, informatizac } \\
\text { que tomam a informação rapidamente à disposição dos operadores }\end{array}$ & $\cdot$ & & $\bullet$ \\
\hline $\begin{array}{l}\text { Presença de retorno de informações entre células e } \\
\text { entre as células e seus clientes/fornecedores }\end{array}$ & $\cdot$ & & $\bullet$ \\
\hline $\begin{array}{l}\text { Projeto de trabalho e outras políticas que permitam aos operadores } \\
\text { tomar aços em resposta a sinais }\end{array}$ & + & & $\bullet$ \\
\hline $\begin{array}{l}\text { Projeto de trabalho e outras politicas (por exemplo, a compensação) } \\
\text { que detêm operadores co-responsáveis pelos resultados }\end{array}$ & 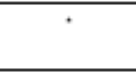 & & $\bullet$ \\
\hline Baixo nuido ambiente & & & $\bullet$ \\
\hline
\end{tabular}

(• ) Capacitador primário, com influência forte e direta nas conexões

(• ) Capacitador secundário, com influência indireta nas conexões

Fonte: Adaptado de Hyer e Brown (1999)

2.1.4 Atributo organizacional

O atributo organizacional considera que a célula deve constituir uma unidade administrativa da empresa, possuindo uma estrutura gerencial claramente vinculada à mesma, incluindo medidas e metas de desempenho, operadores, supervisores e PCP. 
Satoglu, Durmusoglu e Dogan (2006) reforçam esse atributo, afirmando que um princípio básico da CM é dividir o sistema produtivo em subsistemas independentes e semi-autônomos, para que cada um possa responder mais rápido e eficientemente possível às necessidades de produção. De acordo com Hyer e Wemmerlov (2002), as principais vantagens deste atributo são as seguintes: oportunidades de aperfeiçoamento e treinamento com base na interação entre os membros; maior satisfação no trabalho, derivada do enriquecimento e alargamento do trabalho; maior comprometimento e geração de ideias para resolução de problemas.

Hyer e Wemmerlov (2002) enfatizam que a dedicação de recursos técnicos e humanos a um grupo de peças ou produtos é um ponto chave no desempenho das CM. Isto ocorre em virtude do maior comprometimento de operadores com o resultado e com as melhorias. Além disso, segundo o atributo organizacional, cada um dos equipamentos ou um pequeno grupo destes contido na célula, não deveriam ser gerenciados em separado ao restante da célula. Vale ressaltar que este atributo não significa necessariamente que a célula deve ser auto gerenciada, mas apenas que deve ser gerenciada como uma unidade em separado de outras células, equipamentos ou recursos.

\subsection{Produção Enxuta}

\subsubsection{Comentários iniciais}

O foco desse artigo está nas práticas de PE presentes em uma $\mathrm{CM}$, assim, não houve necessidade de uma discussão sobre os princípios e estrutura conceitual da PE. Vale salientar a impossibilidade de abordar todas as práticas de PE com a devida profundidade, onde se manteve uma relação com a estrutura da CM presentes neste item. As práticas destinadas a outros setores da empresa, como a melhoria da relação com cliente-fornecedor e outras. A Figura 2 mostra uma lista de práticas de PE no contexto da CM e uma breve descrição de cada uma delas. 


\begin{tabular}{|c|c|}
\hline Práticas & Definições \\
\hline 1. Autonomação & $\begin{array}{l}\text { Dar a autonomia ao operador ou à máquina de parar o processamento sempre que for } \\
\text { detectada uma anormalidade (GHINATO, 1996). A autonomia dos equipamentos requer a } \\
\text { utilização de dispositivos que tornem os equipamentos capazes de detectar a anormalidade } \\
\text { (erro ou defeito) e parar a produção visando eliminar a propagação de peças defeituosas, } \\
\text { denominados de poka-yokes (LIKER, 2005). A partir da identificação das anormalidades, seja } \\
\text { feita pelos equipamentos ou operadores, são acionados dispositivos que indicam rapidamente } \\
\text { o local e a natureza das situações problema, de denominados de andons (OHNO, 1997). }\end{array}$ \\
\hline $\begin{array}{l}\text { 2. Controle de } \\
\text { Qualidade Zero } \\
\text { Defeitos } \\
\text { (CQZD) }\end{array}$ & $\begin{array}{l}\text { O objetivo do CQZD não é apenas a fabricação de produtos isentos de defeitos, mas o } \\
\text { desenvolvimento de um sistema que seja capaz de produzir em uma postura preventiva à } \\
\text { ocorrência de defeitos (GHINATO, 1996). Os quatro pontos fundamentais do CQZD para que } \\
\text { seja possível a fabricação de produtos livres de defeitos, segundo Shingo (1996) são: (a) a } \\
\text { inspeção na fonte, que identifica os erros geradores de defeitos, onde o controle é aplicado na } \\
\text { sua origem; (b) inspeção realizada em } 100 \% \text { dos produtos em contraposição à inspeção por } \\
\text { amostragem, apesar de que as técnicas de controles por meios estatísticos podem ocorrer } \\
\text { pela impossibilidade de controlar todos os aspectos qualidade de todos os produtos; (c) } \\
\text { redução do tempo entre a detecção de anormalidades e a realização da ação corretiva } \\
\text { necessária; (d) a aplicação de poka-yokes que permitam viabilizar os pontos anteriores. }\end{array}$ \\
\hline $\begin{array}{l}\text { 3. Equipes } \\
\text { multifuncionais }\end{array}$ & $\begin{array}{l}\text { Um pequeno grupo de operadores organizados e gerenciados de forma única, com um } \\
\text { conjunto de atribuições e responsabilidades. Na Toyota, a equipe e o líder da equipe garantem } \\
\text { a realização do trabalho padronizado e das atividades de melhorias (LIKER, 2005). A } \\
\text { multifuncionalidade foi uma das maneiras encontradas pelo STP para adquirir a flexibilidade de } \\
\text { mix e volume de produção necessária para acompanhar as flutuações de demanda dos } \\
\text { clientes (MONDEN, 1998). A multifuncionalidade se torna essencial no desenvolvimento de } \\
\text { uma força de trabalho que possa ser utilizada para estas adaptações às variações de } \\
\text { demanda, exigidas pelo princípio da produção puxada e fluxo contínuo (HARRIS; HARRIS, } \\
\text { 2007). }\end{array}$ \\
\hline 4. Fluxo unitário & $\begin{array}{l}\text { A produção e o transporte serem realizados de modo unitário entre as operações, sendo que } \\
\text { em cada operação realiza apenas o que é exigido pela etapa posterior (LEI, 2002). Miltenburg } \\
\text { (2001) acrescenta que haver, no máximo, uma unidade de produto entre cada uma das } \\
\text { operações internas na CM para ser considerado o atendimento ao fluxo unitário. O fluxo } \\
\text { unitário proporciona a redução no tempo entre a entrada da matéria-prima até o produto } \\
\text { acabado, estimulando a melhora na qualidade e redução de estoques de produtos, além de } \\
\text { estimular a redução no custo e no prazo de entrega (LIKER, 2005). Segundo Askin e Golberg } \\
\text { (2002), o fluxo unitário permite a redução dos tamanhos de lotes, assim, pode ser considerado } \\
\text { como uma das práticas responsáveis pela resposta rápida às variações de demanda, } \\
\text { característica da PE. }\end{array}$ \\
\hline $\begin{array}{l}\text { 5. Melhoria } \\
\text { contínua }\end{array}$ & $\begin{array}{l}\text { A melhoria contínua é colocada em prática pelo kaizen, uma maneira de trabalhar } \\
\text { baseada na busca incansável da perfeição através da eliminação de desperdícios, } \\
\text { praticada por todas as funções hierárquicas de uma empresa, mais visivelmente } \\
\text { pelos operadores (IMAI, 1994). Para Brunet e New (2003), o fato de ser contínuo } \\
\text { resulta no seu papel na jornada infinita através da qualidade e da eficiência, além do } \\
\text { envolvimento da inteligência da força de trabalho torná-lo participativo. O kaizen tem } \\
\text { como objetivo o desenvolvimento em pequenos passos de baixos custos e cíclos } \\
\text { curtos, em um lento e contínuo conjunto de ações de melhorias mantido ao longo do } \\
\text { tempo, e não em mudanças radicais, embora existam possibilidades de melhorias de } \\
\text { maior impacto (BESSANT et al., 1994). }\end{array}$ \\
\hline
\end{tabular}

Revista Produção Online, Florianópolis, SC, v.13, n. 4, p. 1252-1275, out./dez. 2013. 


\begin{tabular}{|c|c|}
\hline Práticas & Definições \\
\hline $\begin{array}{l}\text { 6. Trabalho } \\
\text { padronizado }\end{array}$ & $\begin{array}{l}\text { O tem por objetivo estabelecer uma disciplina e estabilidade, bem como criar uma base para a } \\
\text { melhoria contínua. O trabalho padronizado (TP) permite projetar o trabalho de cada operador } \\
\text { de maneira individual, definir uma seqüência de operação que obedeça à demanda do cliente, } \\
\text { identificando e eliminando os desperdícios nas atividades rotineiras dos operadores (SUZAKI, } \\
\text { 1987). A definição de padrões a serem seguidos pelos operadores possibilita a melhoria } \\
\text { contínua, num momento em que se estabelecem dois fatores: (a) um patamar atingido por } \\
\text { estes padrões se mantém ao longo do tempo; (b) se permite que o aperfeiçoamento seja } \\
\text { contínuo, pois parte de um ponto já estabelecido para as ações de melhorias e o item (a) } \\
\text { dificulta o retorno aos padrões anteriores (SPEAR; BOWEN, 1999). Para Ohno (1997), outra } \\
\text { característica do formulário é que este deve utilizar a gestão visual, sendo afixado em locais } \\
\text { visíveis a cada estação de trabalho. Assim, o TP implica projetar as operações para o } \\
\text { balanceamento de produção, mantendo os tempos de ciclo compatíveis com o takt time, que é } \\
\text { o ritmo de consumo do cliente, em todos os postos da célula, a fim de viabilizar o atendimento } \\
\text { da demanda (MANN, 2005). }\end{array}$ \\
\hline $\begin{array}{l}\text { 7. Troca rápida } \\
\text { de ferramentas }\end{array}$ & $\begin{array}{l}\text { Produzir pequenos lotes de produtos variados, em fluxo contínuo, com uma demanda nivelada } \\
\text { e com flexibilidade de adaptação às variações de demanda requer facilidades na troca de } \\
\text { modelos de produtos (SHINGO, 2000). A prática da troca rápida de ferramentas (TRF), } \\
\text { difundida por Shingo (2000), propõe o estudo detalhado das atividades de setup, com o intuito } \\
\text { de reduzi-las drasticamente, pois essas atividades são consideradas desperdícios. A TRF } \\
\text { consiste em: (a) mapear as atividades de troca de ferramentas; (b) classificá-las em internas e } \\
\text { externas; (c) reduzir ou eliminar cada uma destas atividades; (d) converter as internas e } \\
\text { externas; (e) padronizar o procedimento. }\end{array}$ \\
\hline $\begin{array}{l}\text { 8. Manutenção } \\
\text { produtiva total }\end{array}$ & $\begin{array}{l}\text { A manutenção é um aspecto importante na PE, pois as limitações de tamanho dos estoques } \\
\text { reduzem as possibilidades de absorver ineficiências dos equipamentos, sem que isso afete } \\
\text { produção. Além disso, o funcionamento de uma máquina sob condições precárias pode gerar } \\
\text { produtos defeituosos, o que também afeta o fluxo de produção (GHINATO, 2000). O STP } \\
\text { enfatiza principalmente na manutenção autônoma e preventiva (LIKER, 2005). A manutenção } \\
\text { autônoma consiste de uma manutenção preventiva básica e rotineira executada pelos próprios } \\
\text { operadores, reduzindo a dependência de áreas de apoio (MAGGARD; RHYNE, 1992). A } \\
\text { manutenção preventiva é uma intervenção realizada por pessoal especializado, preparada e } \\
\text { programada antes do acontecimento da falha, (MONCHY, 1989). }\end{array}$ \\
\hline $\begin{array}{l}\text { 9. Produção } \\
\text { puxada } \\
\text { nivelamento de } \\
\text { produção }\end{array}$ & $\begin{array}{l}\text { Um modo de interligar todos os processos produtivos no chão-de-fábrica para que cada } \\
\text { processo fornecedor esteja produzindo no mesmo ritmo que o seu processo cliente, e, assim, } \\
\text { produzindo de acordo com a demanda real (takt time) e com mínimo de desperdícios } \\
\text { (WOMACK; JONES, 1998). Já o nivelamento de produção está relacionado a manter um } \\
\text { padrão repetitivo de sequência de modelos de produtos em termos de mix e volume de } \\
\text { produção, idealmente em lotes unitários. Desta forma, ao invés de produzir cada tipo de } \\
\text { produto apenas uma ou poucas vezes ao mês, o nivelamento busca produzir diariamente cada } \\
\text { tipo de produto (LIKER, 2005). }\end{array}$ \\
\hline $\begin{array}{lr}10 . & \text { Gestão } \\
\text { visual } & \text { de } \\
\text { informações }\end{array}$ & $\begin{array}{l}\text { Qualquer dispositivo que comunique rapidamente se existe algum desvio no padrão e que } \\
\text { indique como o trabalho deve ser executado (LIKER, 2005). A gestão visual é crucial para } \\
\text { proporcionar autonomia e responsabilidade a todos os funcionários, sejam eles operadores do } \\
\text { chão-de-fábrica ou gerentes, difundindo a consciência em eliminar desperdícios, } \\
\text { anormalidades e qualquer outro problema da fábrica (MONDEN, 1998). Henderson e Larco } \\
\text { (1999) acrescentam que, em uma típica fábrica que adota a PE, são facilmente } \\
\text { compreensíveis o fluxo de trabalho, desempenho, problemas e oportunidades. }\end{array}$ \\
\hline
\end{tabular}

Revista Produção Online, Florianópolis, SC, v.13, n. 4, p. 1252-1275, out./dez. 2013. 


\section{MÉTODO DE PESQUISA}

O método de pesquisa foi dividido em três etapas: 1) definir os atributos qualificadores da $\mathrm{CM}$; 2) listar as práticas de PE aplicáveis nas $\mathrm{CM}$; 3) identificar a influência de cada uma das práticas de PE nos atributos qualificadores da CM.

As etapas 1) e 2) foram baseadas em revisões de literatura. $O$ objetivo da etapa 1) foi apresentar uma visão atualizada dos atributos que qualificam uma $\mathrm{CM}$ e foi possível levantar os cinco atributos que foram usados para qualificar uma CM. Já a etapa 2) teve como objetivo listar as práticas de PE aplicáveis em CM. Nestas duas etapas, houve uma preocupação em usar livros e artigos de autores nacionais e internacionais de modo a abranger múltiplas perspectivas e captar a evolução dos temas. Por exemplo, no tema CM, foram usados autores clássicos (BURBIDGE, 1996) e contemporâneos (HYER; BROWN, 1999; HYER; WEMMERLOV, 2002). Esta mesma diretriz também serviu para o tema PE, que apresenta livros clássicos (SHINGO, 1996; OHNO, 1997), contemporâneos (WOMACK; JONES, 1998; LIKER, 2005) e também artigos de revistas científicas nacionais (GODINHO FILHO; FERNANDES, 2004) e internacionais (PETTERSEN, 2009). A ferramenta utilizada para a busca das referências foi o Google Acadêmico.

A etapa 3) partiu dos resultados das etapas 1) e 2) para discutir como as práticas de PE podem influenciar nos atributos que qualificam as $\mathrm{CM}$. Os resultados teóricos da aplicação de cada uma das práticas foram analisados separadamente e, posteriormente, se construiu a Figura 3 para apresentar tais relações. 


\section{RESULTADOS}

\subsection{A Influência das Práticas de PE nos Atributos da CM}

\subsubsection{Autonomação}

$\mathrm{Na} \mathrm{CM}$, assim como em outras formas de organização do trabalho, devem ser tomadas decisões acerca do nível de autonomia dos operadores. Em uma típica CM na $\mathrm{PE}$, a autonomia é caracterizada pelo fato de os operadores que identificarem erros na execução ou produtos com defeitos, pararem a produção (KARLSSON, AHLSTROM, 1999). Por outro lado, as características de uma típica CM não enxuta nesse caso seria o contrário, a identificação de defeitos ser realizada exclusivamente por funcionários responsáveis pela qualidade e os operadores sem a responsabilidade de identificar produtos defeituosos.

Essa prática de PE pode ser relacionada diretamente com os atributos da CM. Por exemplo, uma vez que a produção seja paralisada em caso de produtos defeituosos, o andon é acionado para que haja um auxílio aos operadores que garanta o fluxo de produção. Tal fato contribui para que sejam mantidas as conexões de tempo (reduzindo o tempo de equipamentos parados) e de informação, propiciando a propagação das informações entre os operadores, líderes e áreas de apoio. Além disto, o atributo organizacional é amplamente influenciado, pois torna necessário que os operadores se comuniquem e tomem decisões em conjunto, atribuindo maior responsabilidade e comprometimento para a equipe.

\subsubsection{Controle de Qualidade Zero Defeitos}

O CQZD tem influência direta nas conexões nos atributos de tempo e informação, pois a prevenção, detecção e ação nas anormalidades permitem a redução no tempo de informar sobre os produtos defeituosos. Além disso, a redução dos 
estoques e utilização da CQZD propicia a aplicação de outros capacitadores da CM (ver Figura 1), como a produção e recebimento de componentes conforme especificações e a produção em pequenos lotes. Em sintonia com a prática de Autonomação, o CQZD também amplifica o atributo organizacional, pois, neste caso, os operadores se tornam responsáveis pelo desempenho da célula como um todo, ou seja, pelo andamento do trabalho e pelas melhorias de qualidade e produtividade.

\subsubsection{Equipes multifuncionais}

Nas CM, o alto grau de interação entre operadores, derivado do trabalho em equipes, é o aspecto do sistema social da célula considerado mais importante no seu desempenho, ou seja, enfatizando o atributo organizacional. Deste modo, em uma CM, as métricas de desempenho e as medidas de incentivo aos funcionários devem ser relacionadas à equipe como um todo e não a indivíduos (BIDANDA et al., 2005; HYER; WEMMERLOV, 2002; HELLINGHAUSEN; MYERS, 1998). O atributo organizacional também está relacionado a essa prática de modo a formar o ambiente para a construção da estrutura gerencial requerida para: (a) unificar a responsabilidade através da definição de metas e indicadores visando o comprometimento de todos; (b) lidar com rapidez na tomada de decisão relacionada à produção.

O trabalho em equipe está diretamente ligado às conexões de informação presentes nas $\mathrm{CM}$, por propiciar a comunicação e troca de informações entre operadores. O treinamento multifuncional e rodízio são capacitadores presente nessa prática, com fortes conexões de tempo, pois permitem a flexibilidade de re-alocação de operadores entre operações para lidar com as variações de demanda, com o mínimo possível de esperas e reduzindo os efeitos dos gargalos (HYER; BROWN, 1999).

Dentre os demais capacitadores que mantêm conexões de tempo e informação, se pode citar: (a) os operadores que compartilham informações constantemente; (b) especializados em trabalho em grupo; (c) com entendimento de todas as operações. Tais capacitadores permitem a comunicação e entendimento do fluxo de trabalho na 
CM por parte dos operadores e respostas rápidas para o auxílio entre os membros da equipe.

\subsubsection{Fluxo unitário}

Em CM, a produção e o transporte em grandes lotes acarretam em aumento do tempo de atravessamento e aumento de estoques em processo. A produção e o transporte em menores lotes, objetivando o fluxo unitário, é um dos capacitadores da $\mathrm{CM}$ e facilita as conexões de tempo de forma direta. De forma indireta, tal prática tem influência nas conexões de espaço e informação, pois o acúmulo de estoque na CM resulta em uma área destinada a esse, prejudicando as conexões de espaço, e pode dificultar a comunicação entre operadores no caso de resultar em barreiras visuais. A TG também está presente, pois, para Rother e Harris (2002), a flexibilidade de alteração de mix e volume de produção, sem causar problemas no fluxo unitário, estão vinculados à escolha da família de produtos da CM. Aqueles autores ressaltam que, fluxos erráticos e intermitentes dentro de $\mathrm{CM}$ são frequentes e podem causar o acúmulo de estoques internos e prejudicar o fluxo unitário.

\subsubsection{Melhoria contínua}

As conexões de espaço e informação demonstram estar intimamente ligada ao kaizen, pois facilitam a comunicação entre operadores visando a resolução rápida de problemas. Por outro lado, as conexões de espaço podem ser aprimoradas à medida que os operadores estão treinados para a solução de problemas de fluxo de produção e esperas, consideradas desperdícios e frequentemente objeto de atividades de kaizens. A interação e responsabilidade dos operadores para solucionar problemas em grupo também desenvolvem o atributo organizacional. 


\subsubsection{Trabalho padronizado}

Em relação aos atributos da CM, as conexões de tempo são diretamente influenciadas pelo TP, pois este propicia a aderência aos capacitadores de manuseio eficaz de equipamentos e postos de trabalho balanceados. O manuseio eficaz está ligado à identificação e alocação das atividades entre operadores da melhor forma possível, além de permitir redução dos desperdícios de tempo de movimentação de operadores entre operações. A gestão visual do TP informa de modo completo e preciso o balanceamento dos postos, indicando a presença das conexões de informação, pois permite que os operadores conheçam os postos gargalos, os estoques padrão, o ritmo de produção de cada operador e do processo cliente.

\subsubsection{Troca rápida de ferramentas}

A TRF apresenta conexões em termos de tempo e informação, por possibilitar dois capacitadores relacionados a essa prática, o tamanho de lote pequeno e a redução no tempo de setup. As conexões de tempo são facilmente identificadas, pois o tempo de troca entre modelos influencia diretamente no tempo de esperas, transferências entre operações, na alocação do tempo dos operadores, no tempo de resposta e tempo total para a produção. As conexões de informações demonstram um menor grau, pois estão relacionadas ao conhecimento dos operadores para realizar as atividades de setup.

\subsubsection{Manutenção produtiva total}

A manutenção preventiva é um capacitador da CM vinculado às conexões de tempo, pela forte influência que podem ocasionar as paradas de produção nos fluxos de produção e tempos entre operações. A existência de operadores especializados em manutenção autônoma é um capacitador relacionado às conexões de tempo e 
informação, pois, ao mesmo tempo, garante as condições de funcionamento dos equipamentos e permite o conhecimento dos operadores sobre essa condição, possibilitando a tomada de ação preventiva e corretiva com rapidez.

\subsubsection{Produção puxada e nivelamento de produção}

$\mathrm{Na} \mathrm{CM}$, a produção puxada implica tanto a relação com o processo cliente, ou seja, produzir de acordo com a demanda real desse, quanto ao processo fornecedor, receber componentes de acordo com a demanda da $\mathrm{CM}$. Na produção puxada e no nivelamento de produção estão presentes as conexões de tempo, espaço e informação. A produção de acordo com um ritmo necessário entre clientes e fornecedores, influência nas conexões de tempo por, de forma simultânea, garantir que haja componentes para a fabricação dos produtos (minimizando as perdas de tempos decorrentes de falta de componentes) e que esses não se tornarão excessivos (resultando em um tempo de esperas planejado, que pode ser reduzido).

Em relação às conexões de informação, essas permitem a identificação da situação dos estoques de forma clara e precisa aos operadores em tempo de tomar ações corretivas (conexões de tempo), além possibilitar a verificação de recorrentes faltas ou excessos de estoques. Vale salientar também a presença de conexões de espaço, pois a produção puxada permite a redução de estoques e, consequentemente, que as operações estejam posicionadas mais próximas umas das outras dentro da CM.

Dentre os capacitadores da CM, estão presentes: (a) peças entregues em tempo; (b) a presença de retorno de informações entre células e entre as células e seus clientes/fornecedores. Ambos com influência nas conexões de tempo e informação.

\subsubsection{Gestão visual de informações}

$\mathrm{Na} \mathrm{CM}$, a gestão visual comunica e auxilia os funcionários a responderem com rapidez às mudanças e variações que acontecem no sistema, envolvendo, por exemplo, 
aspectos de procedimentos padrão, tempos padrão, takt time, atendimento à demanda, organização do local de trabalho, controle da qualidade e estoques de componentes (HYER; WEMMERLOV, 2002). Esse fato indica a presença das conexões de tempo e informação associados a essa prática. Além disso, a comunicação é crucial para o desempenho da célula, tanto em termos de comunicação interna, como quanto com outros níveis hierárquicos e com os demais setores da empresa (BIDANDA et al., 2005). Tais conexões estão intimamente relacionadas a quatro capacitadores das CM: (a) operadores que compartilham informações constantemente; (b) Os operadores têm acesso visual a todas as atividades da célula e informação na "linha de visão"; (c) gestão de sistemas de controle visual, auditiva manual, informatizada que tornam a informação rapidamente à disposição dos operadores; (d) projeto de trabalho e outras políticas que permitam aos operadores tomar ações em resposta a sinais.

\subsection{Visão geral dos resultados}

A Figura 3 apresenta de forma resumida as influências identificadas entre as práticas de $\mathrm{PE}$ e os atributos da $\mathrm{CM}$. Vale salientar que as práticas de $\mathrm{PE}$ demonstraram interação com todos os atributos da CM. 
Figura 3 - Interação entre práticas de PE e atributos da CM

\begin{tabular}{|c|c|c|c|c|c|}
\hline \multirow{2}{*}{ Práticas de PE } & \multirow{2}{*}{$\begin{array}{l}\text { Tecnologia } \\
\text { de Grupo }\end{array}$} & \multicolumn{3}{|c|}{ Elementos } & \multirow{2}{*}{$\begin{array}{c}\text { Organiza } \\
\text { cional }\end{array}$} \\
\hline & & Tempo & Espaço & Informação & \\
\hline 1. Autonomação & & $\bar{X}$ & & $\bar{X}$ & $\bar{X}$ \\
\hline $\begin{array}{l}\text { 2. Controle de Qualidade Zero } \\
\text { Defeitos }\end{array}$ & & $x$ & & $X$ & $x$ \\
\hline 3. Equipes multifuncionais & & & & $\mathrm{X}$ & $\mathrm{X}$ \\
\hline 4. Fluxo unitário & $\bar{x}$ & $\bar{x}$ & $\mathrm{X}$ & $\bar{X}$ & \\
\hline 5. Melhoria contínua & & & $\mathrm{X}$ & $\bar{x}$ & $\mathrm{X}$ \\
\hline 6. Trabalho padronizado & & $\mathrm{x}$ & & & \\
\hline 7. Troca rápida de ferramentas & & $\bar{x}$ & & $\bar{x}$ & \\
\hline 8. Manutenção produtiva total & & $\mathrm{X}$ & & $\mathrm{x}$ & \\
\hline $\begin{array}{l}\text { 9. Produção puxada e nivelamento } \\
\text { de produção }\end{array}$ & & $x$ & $x$ & $x$ & \\
\hline 10. Gestão visual de informações & & $\mathrm{x}$ & & $x$ & \\
\hline Total & 1 & & & 9 & 4 \\
\hline
\end{tabular}

Dentre as influências, foi evidenciado que a maioria das práticas de PE tem como objetivo aumentar a presença dos elementos de tempo e informação nas CM. Seja pela detecção rápida de problemas, na atuação na solução de problemas ou no uso de uma quantidade de estoques mínima entre as atividades da célula, a PE busca formar uma unidade gerencial que simultaneamente reduza o tempo de processamento dos produtos e informe constantemente sobre a situação de todos os recursos. Estas características demonstram que as práticas de PE aumentam a presença dos atributos que qualificam uma CM "real" e também os atributos do sistema sócio-técnico.

Em relação ao atributo organizacional e o elemento espaço, estes também são influenciados positivamente pela aplicação das práticas de PE, mas em menor grau, interagindo com quatro e três práticas, respectivamente. Apesar disto, ambos são diretamente relacionados a práticas de melhoria contínua, por exemplo, uma das práticas principais na implantação de PE em CM (SAURIN; MARODIN; RIBEIRO, 2011). 
A TG demonstra ser o atributo influenciado apenas por uma das práticas de PE, o fluxo contínuo. Isto não quer dizer que este atributo não é importante para a PE, mas que possivelmente, a sua influencia esteja em práticas de PE antecessoras ao funcionamento da $\mathrm{CM}$ em si, como na concepção dos produtos e desenho de processos. É conhecida a aplicação de práticas de PE em desenvolvimento de produtos como análise de valor, modularização e padronização, as quais são utilizadas para o design for manufacturing, ou seja, reduzir a complexidade dos produtos e facilitar a produção (JAYARAM; VICKERY; DROGE, 2008). Tais práticas tendem a facilitar a aplicação da TG e posterior criação de CM com melhor desempenho.

\section{CONCLUSÃO}

O presente artigo teve como objetivo investigar como as práticas de PE influenciam nos atributos que qualificam uma CM. Apesar de amplamente defendido na literatura, não foram encontradas discussões ou evidências claras de tais influências. Para isto, foi necessário desenvolver um conceito de $\mathrm{CM}$ que atenda a perspectiva do sistema sócio-técnico, incorporando um atributo técnico e outro social, e também a presença dos elementos de tempo, espaço e informação, que definem uma "célula real". Dentre as 10 práticas de PE presentes em uma CM, se identificou que 9 delas influenciam no atributo Informação e oito no atributo Tempo, aqueles que sofrem maior influência das práticas de PE. Os atributos espaço e organizacional também são influenciados na aplicação das práticas de PE, com três e quatro práticas que atuam diretamente nestes. $\mathrm{O}$ atributo que TG é influenciado por apenas uma prática de PE, o Fluxo Contínuo.

A pesquisa se limita a um ensaio teórico e abre espaço para estudos futuros de modo a validar e enriquecer as discussões sobre a influência das práticas de PE nas CM. Sugere-se que o tema seja explorado por meio de entrevistas com especialistas e um ou múltiplos estudos de caso de modo a construir um modelo robusto que evidencie tais influências. $O$ presente artigo também abre espaço para a construção de um 
método para avaliar CM de acordo com os atributos propostos. Por outro lado, também pode ser utilizado como ponto de partida para o desenvolvimento de um método para avaliar como as práticas de PE melhoram o desempenho da CM, levando em conta indicadores de custo, qualidade, produtividade e volume de produção, por exemplo.

\section{REFERÊNCIAS}

ASKIN, R. G.; GOLDBERG, J. B. Design and analysis of a lean production systems. New York: John Wiley and Sons, 2002.

BESSANT, J. et al. Rediscovering continuous improvement. Technovation. v.14, n.1, p.17-29, 1994.

BIDANDA, B. et al. Human related issues in manufacturing cell design, implementation, and operation: a review and survey. Computers and Industry Engineering, v. 48, p. 507-523, 2005.

BLACK, J.T. Design rules for implementing the Toyota production system. International Journal of Production Research, v.45, n.16, p.3639-3664, 2007.

BRUNET, A. P; NEW, S. Kaizen in Japan: an empirical study, International Journal of Operations and Production Management, v.23, n.12, p.14-26, 2003.

BURBIDGE, J L. The first step in planning group tecnology. International Journal of Production Economics, v.43, p.261-266, 1996.

CARDOZA, E.; CARPINETTI, R. Indicadores de desempenho para o sistema de produção enxuto. Revista Produção Online. v.5, n.2, 2005.

COELHO, A. S.; BRANCO, R. M.; RODRIGUES, G. S. Aprimoramento da produtividade de sistemas de manufatura e aplicação de algoritmos genéticos na solução de problemas de agrupamentos celulares. Revista Produção Online. v.6, n.3, 2006.

DROLET, J; ABDULNOUR, G, RHEAULT, M. The cellular manufactoring evolution. Computers and Industrial Enginnering, v.31, n.1/2, p.139-142, 1996.

GHINATO, P. A study on the work force assignment in U-shaped production systems. Tese (Doutorado)- Graduate School of Science and Technology, Kobe University, 1998. 
GHINATO, P. Sistema Toyota de produção: mais que simplesmente just-in-time. Caxias do Sul: Editora da Universidade de Caxias do Sul, 1996.

GODINHO FILHO, M.; FERNANDES, F. C. F. Manufatura enxuta: uma revisão que classifica e analisa os trabalhos apontando perspectivas de pesquisas futuras. Gestão \& Produção Revista \& Produção, v.11, p.1-19, 2004.

HARRIS, C.; HARRIS, R. Developing a lean workforce: a guide for human resources, plant managers, and lean coordinators. New York: Productivity Press, 2007.

HELLINGHAUSEN, M.; MYERS, J. Empowered employees: a new team concept. Industrial Management, v.40, n.5, p. 21-23, 1998.

HENDERSON, B. A.; LARCO, J. L. Lean Transformation. Richmond: The Oaklea Press, 1999.

HINES, P; HOLWEG, M; RICH, N. Learning to evolve: A review of contemporary lean thinking. International Journal of Operations \& Production Management, v.24, n.10, p 994-1011, 2004.

HYER, N L.; BROWN, K A. The Discipline of real cells. International Journal of Operations Management, v.17, p.557-574, 1999.

HYER, N L.; BROWN, K A.; ZIMMERMAN, S. A social-technical systems approach to cell design: case study and analysis. Journal of Operations Management, v.17, p.179203, 1999.

HYER, N.; WEMMERLOV, U. Reorganizing the factory: competing through cellular manufacturing. New York: Productivity Press, 2002.

IMAI, M. Kaizen: a estratégia para o sucesso competitivo. São Paulo: IMAM, 1994.

JAYARAM, J; VICKERY, S; DROGE, C. Relationship building, lean strategy and firm performance: an exploratory study in the automotive supplier industry. International Journal of Production Research, v.46, n. 20, p.5633-5649, 2008.

KARLSSON, C.; AHLSTROM P. Assessing changes towards lean production. International Journal of Operations and Production Management. v.16, n.2, 1996.

LEl. Léxico lean: glossário ilustrado para praticantes do pensamento lean. São Paulo: Lean Institute Brasil, 2003.

LIKER, J. K. O Modelo Toyota: 14 princípios de gestão do maior fabricante do mundo. Porto Alegre: Bookman, 2005. 
MAGGARD B. N.; RHYNE D. M. Total productive maintenance: a timely integrations of production and maintenance. Production and Inventory Management Journal, v.33, n.4, 1992.

MANN, D. Creating a lean culture: tools to sustain lean conversion. New York: Productivity Press, 2005.

MARODIN, G; SAURIN, T. Modelo de avaliação de arranjos físicos sob a ótica da manufatura celular: MMCEL. Revista Gestão Industrial, Universidade Tecnológica Federal do Paraná, v.3, n.3, 2007.

MASKELL, B; BAGGALEY, B. Practical lean accounting: a proven system for measuring and managing the lean enterprise. New York: Productivity Press, 2004.

MILTENBURG, J. U-shaped production lines: A review of theory and practice. International Journal of Production Economics, v.70, p.201-214, 2001.

MONCHY, F. A função manutenção: formação para a gerência da manutenção industrial. São Paulo: Durban, 1989.

MONDEN, Y. Toyota production system: practical approach to production management. Norcross: Industrial Engineering and Management Press, 3 ed.,1998.

MOTWANI, J. A business process change framework for examining lean manufacturing: A case study. Industrial Management and Data Systems, v.103, n.5, 2003.

NOGUEIRA, M., G.; SAURIN, T. A. Proposta de avaliação do nível de implementação de típicas práticas da produção enxuta em uma empresa do setor metal-mecânico.

Revista Produção Online. v.8, n.2., 2008.

OHNO, T. O sistema Toyota de produção: além da produção em larga escala. Porto Alegre: Artes Médicas, 1997.

PAPADOPOULOU, T; OZBAYRAK, M. Leanness experiences from the journey to date. Journal of Manufacturing Technology Management, v.16, n.7, 2005.

PATTANAIK, L. N; SHARMA, B. P. Implementing lean manufacturing with cellular layout: a case study. International Journal of Advanced Manufacturing Technology. v.42, n.7-8, p.772-779, 2009.

PETTERSEN, J. Defining lean production: some conceptual and practical issues. The TQM Journal, v.21, n.2, p. 127-142, 2009. 
RAO, M. A. et. al. Recognition of machine cells in a group technology layout using selforganizing neural networks. Institute of Mechanical Engineers, v.215, part B, 2001.

ROTHER, M; HARRIS, R. Criando fluxo contínuo. São Paulo: Lean Institute Brasil, 2002.

SANTOS, A.; MOSER, L.; TOOKEY, J.E. Applying the Concept of Mobile Cell Manufacturing on the Drywall Process. Proceedings IGLC-10, Gramado, Brazil, 2002.

SATOGLU, S. I; DURMUSOGLU, B.; DOGAN, I. Evaluation of the conversion from central storage to decentralized storages in cellular manufacturing environments using activity-based costing. International Journal of Production Economics, v.103, p.616632, 2006.

SAURIN, T; MARODIN, G; RIBEIRO, J. A framework for assessing the use of lean production practices in manufacturing cells. International Journal of Production Research, v.49, n.11, 2011.

SHAFTER, S. M.; MEREDITH, J. M.; MARSH, R. F. A Taxonomy for alternative equipment groupings in batch environments. Omega, v.23, n.4, p. 361-376, 1995.

SHERIDAN, J. World-class manufacturing. Industry Week, v.239, n.13, p.36-46, 1990.

SHINGO, S. O Sistema Toyota de produção do ponto de vista da de engenharia produção. Porto Alegre: Bookman, 1996.

SHINGO, S. Sistema de troca rápida de ferramenta: uma revolução nos sistemas produtivos. Porto Alegre: Bookman, 2000.

SPEAR, S; BOWEN, H. K. Decoding the DNA of the Toyota production system. Harvard Business Review , p.97-106, Set./Out. 1999.

SUZAKI, K. The new manufacturing challenge. New York: Free Press, 1987.

WEMMERLOV, U; JOHNSON, D. J. Cellular manufacturing at 46 users plants: implementation experiences and performance improvements. International Journal of Production Research, v.35, n.1, p.29-49, 1997.

WOMACK, J. P; JONES, D. T. Mentalidade enxuta nas empresas: elimine 0 desperdício e crie riqueza. Rio de Janeiro: Campus, 1998.

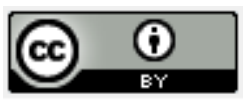

Artigo recebido em 14/01/2012 e aceito para publicação em 18/10/2013. 